\title{
Indicators to measure the climate change adaptation outcomes of ecosystem-based adaptation
}

\author{
Camila I. Donatti ${ }^{1}$ - Celia A. Harvey ${ }^{1,2} \cdot$ David Hole $^{1} \cdot$ Steven N. Panfil ${ }^{3}$. \\ Hanna Schurman ${ }^{4}$
}

Received: 18 July 2018 / Accepted: 26 September 2019 / Published online: 27 November 2019

(C) Springer Nature B.V. 2019

\begin{abstract}
Ecosystem-based adaptation (EbA) is the use of biodiversity and ecosystem services as part of a strategy to help people adapt to climate change. Despite the potential of EbA to provide adaptation benefits, there is a lack of consensus on how to measure the success of this approach. This paper reviews the intended adaptation outcomes and indicators used by ongoing and completed EbA projects and addresses the following questions: (a) where have EbA projects been implemented? (b) what activities have been conducted by EbA projects? (c) what adaptation outcomes are EbA projects seeking to achieve? (d) how have the impacts of EbA projects been measured and evaluated? and (e) what is the set of indicators that can capture the diversity of adaptation outcomes achieved by EbA? To identify the adaptation outcomes provided by EbA and the indicators that could be used to measure such outcomes, we reviewed 58 EbA projects implemented globally, and obtained recommendations from experts on what indicators should be measured. We identified 13 adaptation outcomes that could be achieved through EbA, such as reducing the loss of assets of coastal communities due to extreme events. We identified seven indicators to monitor the success of EbA in achieving adaptation outcomes. Our review suggests that there is a strong need to better articulate the adaptation outcomes that EbA projects seek to achieve, to use a common set of specific indicators to track these outcomes, and to fund the monitoring of long-term EbA projects.
\end{abstract}

Keywords Climate change adaptation outcomes $\cdot$ Ecosystem-based adaptation $\cdot$ EbA effectiveness · Monitoring and evaluation

\section{Introduction}

Climate change is impacting social and ecological systems, as well as the interactions between them. The goal of the 2015 UNFCCC (United Nations Framework Convention on Climate

Electronic supplementary material The online version of this article (https://doi.org/10.1007/s10584-01902565-9) contains supplementary material, which is available to authorized users.

Camila I. Donatti

cdonatti@conservation.org

Extended author information available on the last page of the article 
Change) Paris Agreement is to strengthen responses to keep the global temperature rise up to $2{ }^{0} \mathrm{C}$ above pre-industrial levels and to pursue efforts to limit the temperature increase to $1.5^{\circ} \mathrm{C}$ (United Nations 2015). However, even if either of those targets is achieved, climate change adaptation will still be needed, as many places have already experienced drastic impacts due to warmer temperatures, sea level rise, and stronger and more frequent extreme events (Mimura et al., 2014).

One promising approach for climate change adaptation is ecosystem-based adaptation (UNEP 2012; World Bank 2009). Ecosystem-based adaptation (hereafter "EbA") refers to "the use of biodiversity and ecosystem services as part of an overall adaptation strategy to help people adapt to the adverse effects of climate change" (CBD 2009). It includes the conservation, restoration, and sustainable management of ecosystems, ecosystem processes, and biodiversity to address the impacts of climate change on people's lives and livelihoods. Examples of EbA include the conservation of mangroves to protect people against storms, the reforestation of hillsides to prevent landslides under extreme rainfall events, and the use of shade trees in coffee plantations to maintain production under rising temperatures, among others (Andrade et al. 2010; Jones et al. 2012; Vignola et al. 2015). In addition to delivering adaptation outcomes, EbA can provide economic, social, and environmental co-benefits (Moberg and Rönnbäck 2003; World Bank 2009) and contribute to climate change mitigation (Jones et al. 2012; Mori et al. 2013). It is also considered to be a cost-effective (Mohamed 2007; Emerton et al. 2009; Munroe et al. 2012) and a low-regret option for climate adaptation (Jones et al. 2012).

Even though the protection, restoration, and management of ecosystems have been used by people to cope with climatic variability and change for many years, the use of the term EbA and the attention this concept has received from policy makers, environmental and development organizations, practitioners and donors is relatively new (see CBD 2009; Munang et al. 2013; UNEP 2015). EbA has been promoted within the UNFCCC policy discussions and in national and international fora since 2009 and is explicitly mentioned in the nationally determined contributions (NDCs) of 103 countries as part of the Paris Agreement (IIED 2018).

Despite the potential of EbA to provide adaptation outcomes and the growing interest by governments in this approach, there is still a limited evidence base on whether many types of EbA interventions can be considered effective in helping people adapt to climate change. This lack of clear evidence is considered a barrier to the broadscale use of EbA (Reid 2011; Naumann et al. 2013; Doswald et al. 2014; Milman and Jagannathan 2017). In contrast to climate mitigation, climate change adaptation can be applied in a wide range of contexts, and hence lead to a very broad range of outcomes (e.g., reducing disaster risk, reducing food insecurity, reducing water scarcity driven by climate change) (Jones et al. 2012; Ford et al. 2015), encompassing both social and biophysical impacts (McKinnon and Hole 2015). The broad range of adaptation activities and outcomes precludes the use of a single common reference metric or indicator to measure adaptation outcomes in the same way that mitigation is measured (i.e., in terms of avoided greenhouse gases emissions) (Ford et al. 2013; Noble et al. 2014; Ford et al. 2015; Leiter et al. 2019).

The identification of a set of candidate evaluation indicators for adaptation can be complicated. This is because what constitutes success following an adaptation intervention changes over space and time, as climate change impacts differ across sites, temporal and spatial scales, and affects a series of sectors (Spearman and MacGray 2011; Leiter and Pringle 2018; Leiter et al. 2019). Furthermore, if proposed indicators are too narrow, they may not capture all adaptation outcomes. If the indicators are too broad, they may not be useful in tracking adaptation success. Those are not, however, problems specific to EbA, but apply to the measurement of adaptation in general (Olivier et al. 2013). 
Nevertheless, focusing on a specific approach, such as EbA, and on indicators that can be used at the project level, may facilitate the identification of a set of indicators for tracking adaptation outcomes. The definition of adaptation outcomes that can be achieved through $\mathrm{EbA}$, and the indicators that can be used to monitor them, are critical for providing information on whether this approach is delivering the expected adaptation outcomes (Spearman and MacGray 2011; McKinnon and Hole 2015; Raymond et al. 2017), as well as for understanding which EbA interventions are performing well, hence enabling a more targeted focus of future EbA activities. Furthermore, the identification of adaptation outcomes could help practitioners to better plan and monitor their EbA projects and help practitioners to design EbA interventions that lead to specific adaptation outcomes. The identification of indicators could assist funders in assessing the adaptation impacts of their EbA investments (SNIFFER 2012) and help policy makers evaluate progress towards countries' adaptation goals.

This paper is an attempt to help identify and monitor the multiple adaptation outcomes that can be achieved by EbA by compiling information on the intended adaptation outcomes and indicators used by EbA projects. The paper aimed to answer the following questions: (a) where have EbA projects been implemented? (b) what activities have been conducted by EbA projects? (c) what adaptation outcomes are EbA projects seeking to achieve? (d) how have the impacts of EbA projects been measured and evaluated to date? and (e) what is the set of indicators that can capture the broad diversity of adaptation outcomes achieved by EbA?

\section{Methods}

\subsection{Review of EbA projects}

To identify the intended adaptation outcomes of EbA projects and the indicators of adaptation "success" that the projects used to evaluate their overall goals, we reviewed completed and ongoing EbA projects found in three major donor databases (UNFCCC 2015, UNEP: http://ebaflagship.unep.org/, and GEF: https://www.thegef.org/projects?search_api_views_ fulltext=ecosystem-based+adaptation). We focused on these databases as they are the largest existing databases for adaptation projects. Projects were included in the review if they were (a) self-identified as EbA projects (i.e., the term EbA had to be explicitly listed in the project title or in the project description), (b) included as examples of EbA projects in a compilation of information created by the UNFCCC (UNFCCC 2015), or (c) identified as EbA projects by donors. Projects included in the review also had to have an implementation component (i.e., the project had to implement restoration, protection or management of ecosystems, ecosystem processes and biodiversity to help people adapt to climate change, and/or implement soft measures to support those).

We opted to focus on EbA projects only (and not extend the review to projects that are using other terms such as green infrastructure and ecological infrastructure) and use the criteria above to avoid the need for authors to interpret whether or not the project was implemented to address the adaptation of people. Once EbA projects were identified, we then searched for project documents in the same databases or in other online platforms and collected the following information: (i) location (globally) of project implementation, (ii) EbA activities implemented, (iii) climate hazard addressed, iv) beneficiaries of activities, v) expected climate change adaptation outcomes, and (vi) indicators monitored. 


\subsection{EbA activities implemented}

Through our review, we identified the types of EbA activities planned or implemented by each project. We then summarized information about the types and locations of these activities.

\subsection{Adaptation outcomes that can be achieved through EbA}

We defined an adaptation outcome as the reduction in harm, the reduction in the risk of harm, or the realization of benefits to address climate variability and change (UKCIP 2004). In other words, the outcome is the climate change adaptation goal that is to be achieved through the implementation of the EbA intervention. Examples of adaptation outcomes that could be achieved through EbA include a "reduction in the impacts of elevated drought severity on water quantity delivered to humans through the conservation or restoration of cloud forests" or a "reduction in the damage to coastal communities due to an increased intensity of tropical storms through the restoration of coastal mangrove" (see Table 1 for more examples) (Emanuel 2005; Jones et al. 2012). These project outcomes are different than project outputs, which simply measure the short-term success of project activities, such as the increased number of farmers implementing certain agricultural practices, or the number of hectares of mangrove restored (see mangrove example in McKinnon and Hole 2015) (Fig. 1).

For each project, we identified the adaptation outcome(s) that the EbA intervention(s) aimed to achieve. We presented a preliminary set of adaptation outcomes identified through the review in a workshop held on October 2016 in Arlington, VA, USA, with experts in the field of climate change adaptation. The purpose of the workshop was to (a) present the adaptation outcomes found through the review of EbA projects, (b) review and identify the indicators that could be used to measure those outcomes, and (c) discuss ways of promoting the adoption of a common set of adaptation indicators by donors, policy makers, and practitioners for EbA projects. Experts from the following institutions participated in the workshop: Conservation International (CI), World Resources Institute (WRI), Arizona State University (ASU), United States Agency for International Developement (USAID), French Agricultural Research Centre for International Development (CIRAD), United Nations Environment Programme (UNEP), Deutsche Gesellschaft für Internationale Zusammenarbeit (GIZ), Tierra Resources, The Nature Conservancy (TNC), Adaptation Fund, Programme Office of the International Climate Initiative (IKI), and the International Union for Conservation of Nature (IUCN).

\subsection{Indicators used to track EbA activities implemented by EbA projects}

To understand how projects are monitoring or planning to monitor the results of their EbA activities, we compiled a list of the indicators that each project used to track progress towards overall project goals. We further divided those indicators into output indicators and outcome indicators to assess the proportion of projects that are using each type of indicators. Output indicators are those that simply measure the short-term quantitative success of project activities (such as hectares of rangeland restored or number of farmers trained in certain agricultural practices), whereas outcome indicators are those that measure the effects on ecological or social systems resulting from project activities (such as reduced loss of assets, or reduced impacts of climate change on livestock and crop production, see suppl. material).

Outcome indicators collected through our review were used to prepare an initial list of indicators that could be used to measure the adaptation outcomes of EbA. To minimize the 


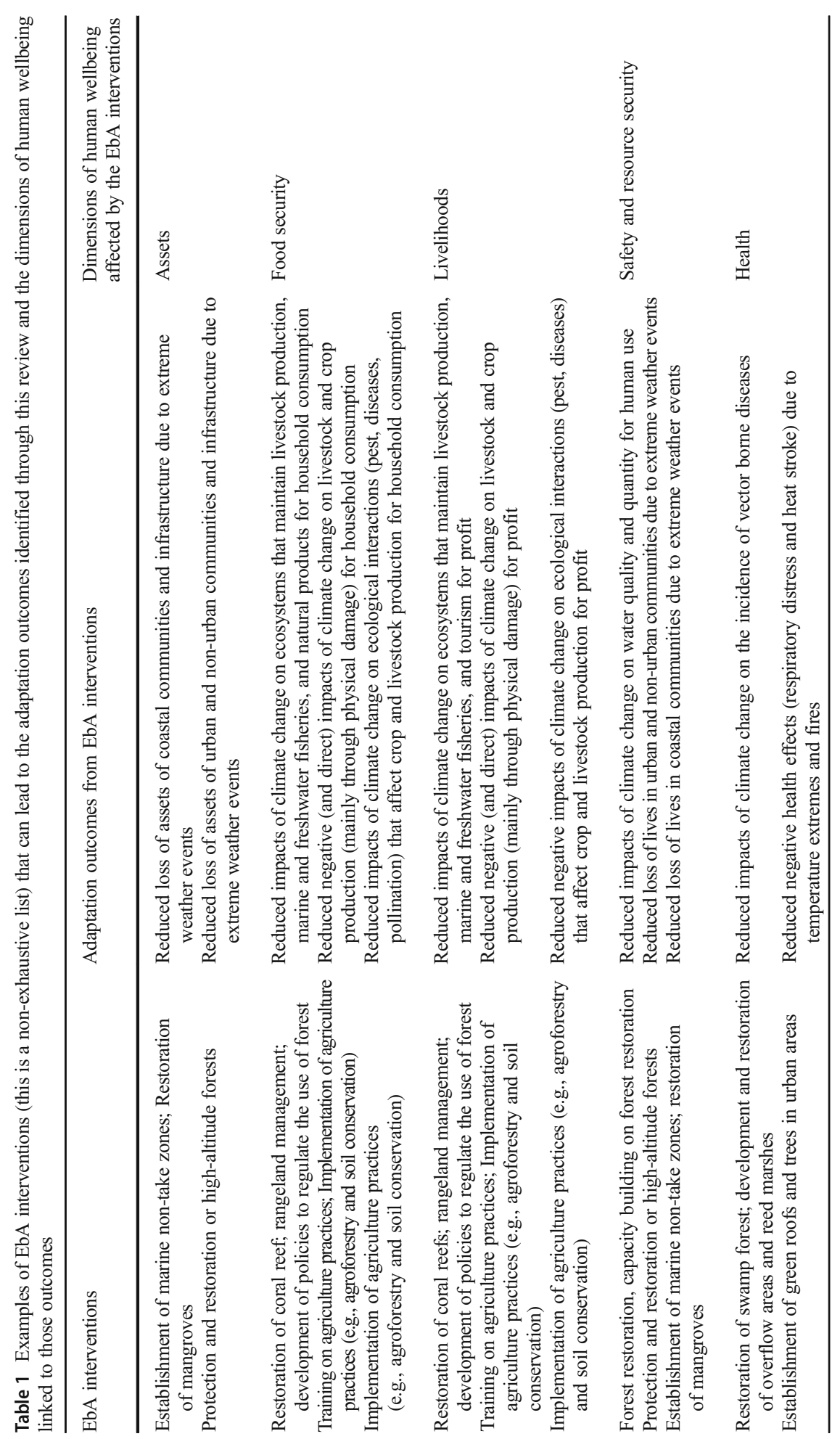



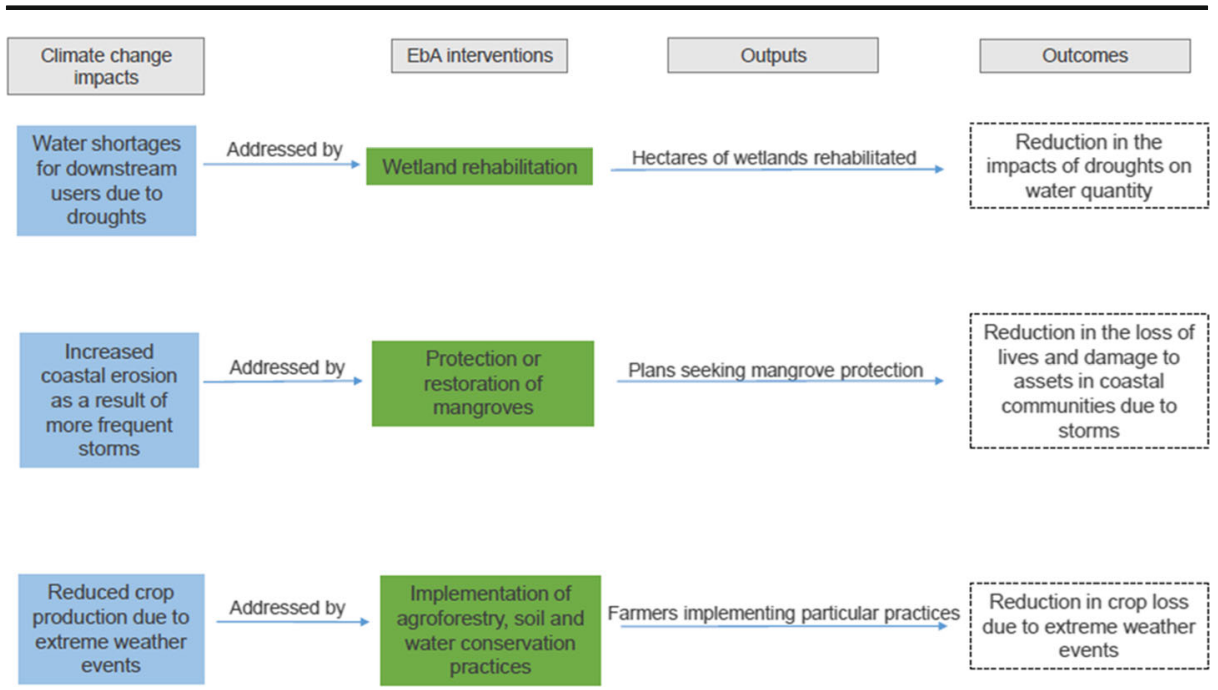

Fig. 1 Examples of EbA interventions implemented to address specific climate change impacts, and the outputs and outcomes that can be achieved through EbA implementation

number of indicators suggested, we aimed to develop one indicator for each adaptation outcome that we identified. Using this initial list, we opted to drop, maintain, or improve those indicators based on the following criteria: (a) the indicators had to provide information that directly addressed the achievement of the adaptation outcome, (b) there had to be feasible ways of measuring the indicators, and (c) the indicators had to be aligned, to the extent possible, with indicators already required by donors (i.e., Global Environmental Facility, Green Climate Fund, International Climate Initiative, United States Agency for International Development), identified by well-known institutions to measure human health and wellbeing (i.e., World Health Organization, Food and Agriculture Organization of the United Nations), identified in peer-reviewed publications (i.e., Kahn 2003) and/or used to measure the targets of the Sustainable Development Goals and of the Sendai Framework for Disaster Risk Reduction.

This preliminary list was then reviewed at the expert workshop. The experts were divided in small groups, and each group reviewed all the indicators in the list and instructed to identify the best indicator to assess each of the adaptation outcomes. Suggestions of how indicators could be modified, and suggestions of new indicators were captured in tables. This information was then discussed in plenary to come up with an agreed set of indicators. The authors of this paper resolved conflicting suggestions provided during the workshop and came up with the final list of suggested indicators presented here.

\section{Results and discussion}

\subsection{Where have EbA projects been implemented?}

We identified $58 \mathrm{EbA}$ projects, for which information was found in 55 documents. In several cases, more than one document was used to gather information about one project. Conversely, in other instances, a single document was used to gather information about multiple projects. The 58 projects represent all those that were listed in the UNFCCC, UNEP, and GEF databases 
from January 2005 up to August 2016, for which documents were available online and EbA interventions had been implemented. Twenty-nine projects were self-identified as EbA projects, 25 were listed as EbA in the project compilation provided by UNFCCC, and four were identified as EbA projects by donors.

Of the 58 projects we reviewed, fifteen were implemented in Africa, eleven in Asia, nine in South America, six in Central America, six in Europe, five in Oceania, four in North America, one in the Caribbean, and one in the Middle East (Fig. 2). Four projects were implemented in more than one geographic region and eight in more than one country. Forty-seven projects focused on a single ecosystem, and eleven of them on more than one ecosystem. Twelve were implemented in tropical forests, twelve in wetlands, ten in mangroves, six in coral reefs, four in rangelands, three in sand dunes, three in lagoons, two in savannahs, one in seagrasses, one in temperate forest, one in flooded forest, and one in peatlands. Eleven projects focused on agroecosystems, three on urban areas and five on species rather than ecosystems.

Examples of project goals presented in project documents included the following: "reduce the vulnerability of the agricultural system to drought and other extreme precipitation events"; "help communities adapt to increased flooding and storm"; "increase the resilience of human population to sea level rise, and the risk of stronger, more frequent hurricanes and river flooding as a result of climate change"; and "protect communities from erosion and flooding" (see Table 1 suppl. material).

\subsection{What are the activities implemented by EbA projects?}

The 58 projects we reviewed either implemented or were planning to implement a total of 109 EbA interventions. We classified these EbA interventions into two types: "EbA activities on the ground" and "EbA-enabling activities." Both types of interventions, "EbA activities on the ground" and "EbA-enabling activities," are important for moving EbA forward. Whereas the interventions on the ground provide evidence for the provision of adaptation outcomes, the

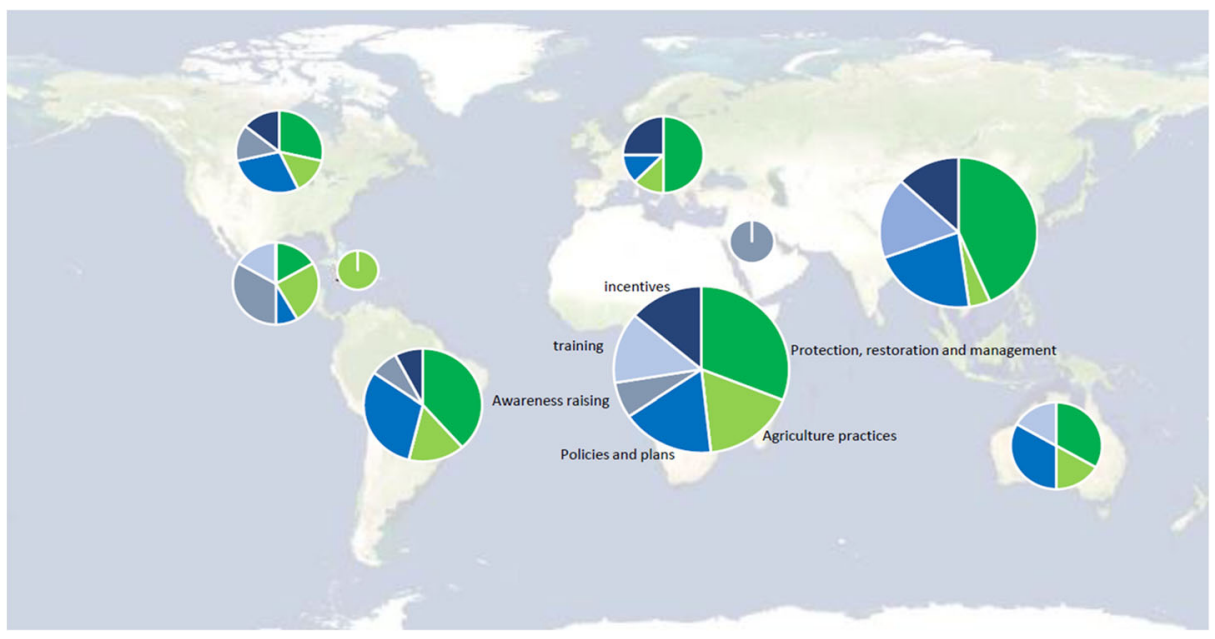

Fig. 2 An overview of $58 \mathrm{EbA}$ projects examined in this paper. The size of the circles corresponds to the number of projects implemented in each region (Africa: $n=15$, Asia: $n=11$, South America: $n=9$, Central America: $n=$ 6, Europe $n=6$, Oceania: $n=5$, North America: $n=4$, Caribbean: $n=1$; and Middle East: $n=1$ ), while colors indicate the specific EbA activities implemented by the different projects in each region 
EbA-enabling activities can help inform the regulations and build the social and institutional capacities which are keys for supporting EbA interventions.

"EbA activities on the ground" included (a) the protection, restoration, and management of ecosystems, ecosystem processes and biodiversity to help people adapt to climate change and (b) the implementation of specific agricultural practices (e.g., mulching, use of terraces, use of trees in plantation) (Harvey et al. 2017) or use of new crop varieties to help people adapt to climate change (see Vignola et al. 2015). "EbA-enabling activities" included (a) policies or plans for the protection, restoration and management of ecosystems, ecosystem process and biodiversity or for the implementation of specific agricultural practices or new crop varieties to help people adapt to climate change; (b) awareness-raising activities regarding the protection, restoration, and management of ecosystems, ecosystem processes and biodiversity or for the implementation of specific agricultural practices or new crop varieties to help people adapt to climate change; (c) training on the protection, restoration and management of ecosystems, biodiversity, ecosystem services, and species or on the implementation of specific agricultural practices or new crop varieties to help people adapt to climate change; and (d) the provision of incentives for the protection, restoration, and management of ecosystems, ecosystem processes and biodiversity or for the implementation of specific agricultural practices or new crop varieties to help people adapt to climate change.

The 58 projects had a similar percentage of "EbA activities on the ground" (49\%) and "EbA-enabling activities" (51\%) planned. The most common activities were the protection, restoration, and management of ecosystems, and the development of policies and plans targeting ecosystem management. Examples of "EbA activities on the ground" included the reforestation of degraded areas to prevent floods under extreme rainfall events $(n=29$ projects), the implementation of soil conservation practices to increase the resilience of farmers to droughts $(n=10)$, and the conservation of mangroves to protect coastal communities against storms $(n=4)$. In all continents, except Europe and South America, most of project activities were "EbA-enabling activities," such as training of managers of protected areas on the benefits of an ecosystem approach to climate change adaptation $(n=6)$, the development of policy guidelines for ecological restoration $(n=3)$, and the provision of incentives to landowners to manage forests to enhance their adaptation benefits $(n=3)$.

\subsection{What adaptation outcomes are EbA projects seek to achieve?}

We identified a total of 54 adaptation outcomes (Table 1 suppl. material). As not all the projects clearly identified the adaptation outcomes that would be achieved through EbA implementation, these had to be inferred from other information extracted from project documents, including the climate change impact addressed, the nature of the activities implemented and the beneficiaries of those activities (Fig. 3).

Since EbA aims to help people adapt to climate change (CBD 2009), we organized the adaptation outcomes identified into "dimensions of human wellbeing." These dimensions were based on a pre-existing typology of domains of human wellbeing (i.e., "economic living standards," "material living standards," "health and food security," "security and safety," "culture and spirituality," "education," "social relations," "freedom of choice," "subjective wellbeing," and "governance and equity"; see McKinnon et al. 2016 for details). The McKinnon et al. (2016) approach was selected because it focuses on domains of human wellbeing that are related to nature conservation.

We identified where each of the 54 adaptation outcomes fit under this preexisting list of domains of human wellbeing. We kept the domains that were related to the adaptation outcomes 


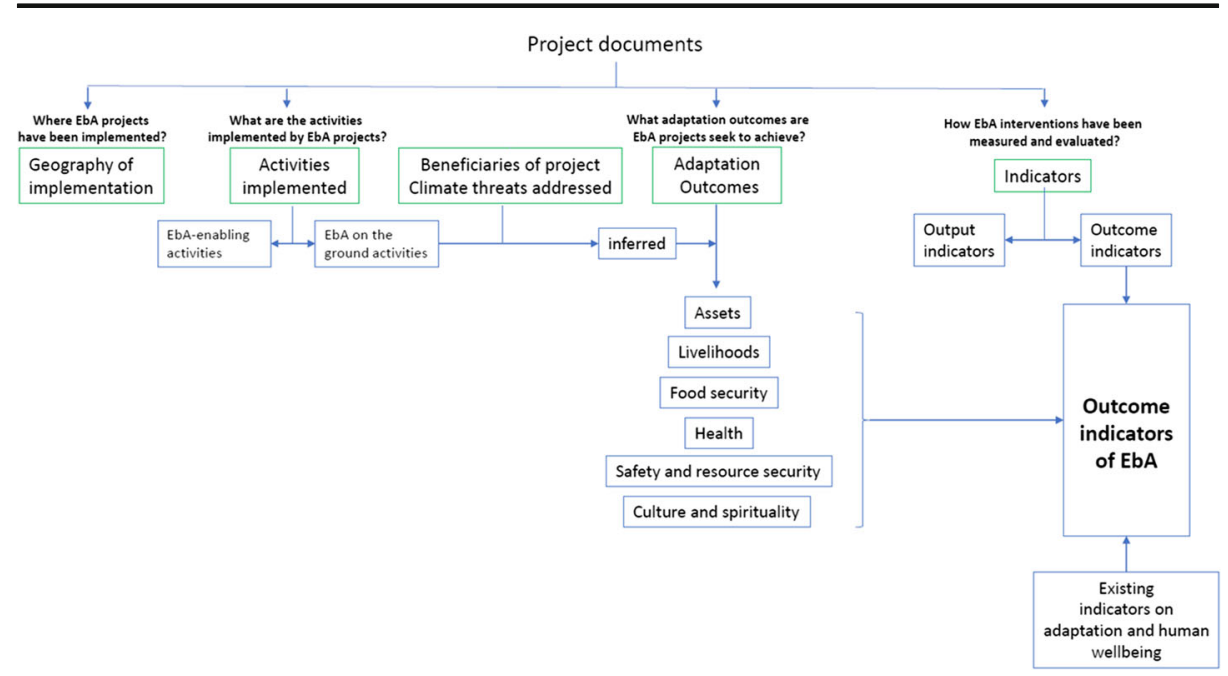

Fig. 3 Information collected from project documents (in green), and how this information was used to define the adaptation outcomes of $\mathrm{EbA}$ and the list of indicators to measure such outcomes (the complete list of outcomes and indicators from project documents are in Table 1 of the supplementary material)

we identified (i.e., "economic living standards," "material living standards," "health and food security," "security and safety"), and re-named or split some to make them more clearly associated with the adaptation outcomes that we have identified through our review. For example, we renamed "material living standards" as "assets" and split "health and food security" into "health" and "food security." We also changed the name of the typology from "domains" to "dimensions" of human wellbeing to make a distinction between the typology presented here from the typology presented in McKinnon et al. (2016). These 54 adaptation outcomes fell into six dimensions of human wellbeing: "assets" with $33 \%$ of the outcomes identified, "food security" (29\%), "livelihoods" (14\%), "safety and resource security" (14\%), and "health" (10\%).

As several of the outcomes were relatively like one another, we further organized them in 13 unique adaptation outcomes (Table 1). For example, "help communities adapt to increased flooding and storms, along with the effects on their livelihoods," "reduce the vulnerability of coastal communities to coastal erosion" and "reduce climate and anthropogenic driven coastline erosion" all fit into the adaptation outcome of "reducing the loss of assets of coastal communities and infrastructure due to extreme weather events." Our final list of adaptation outcomes includes 3 that refer to "food security," 3 to "livelihoods," 3 to "safety and resource security," 2 to "assets," and 2 to "health" (Table 1).

All five dimensions of human wellbeing that we used to organize the adaptation outcomes of EbA are affected by climate change and have a clear connection with people's adaptation to climate change. For example, a reduction in livestock and crop production and fisheries affect food security and livelihoods and are associated with flooding (Eckard et al. 2013), droughts (Matthews and Matthews 2003; Rockstrom 2003; Baro and Deubel 2006; Easterling et al. 2007; Albert et al. 2013; Wetz and Yoskowitz 2013; Maystadt and Ecker 2014; Golmohammadi 2016), storms (Mainville at al. 2003), fires (Minnegal and Dwyer 2000; Rossati 2017), heatwaves (Nardone et al. 2010; Morignat et al. 2014; Vitali et al. 2015), and sea level rise (Olsson et al. 2014; Wong et al. 2014). The production may also be impacted by the long-term changes in terrestrial and oceanic temperature (Aggarwal 2008; Brander 2007; Lobell et al. 2011). 
A reduction in water quality and quantity that affects water security is associated with flooding (Kovats et al. 1999; Shimi et al. 2010; Embrey et al. 2012), heatwaves (Huber et al. 2012), and droughts (Shen et al. 2007; Benotti et al. 2010) as well as long-term changes in precipitation (Park et al. 2010; Patz et al. 2000). Deaths in coastal and non-coastal areas are related to hurricanes, typhoons, storms (Karim and Mimura 2008; Brecht et al. 2012; Yates et al. 2014), and associated flooding (McGranahan et al. 2007), landslides (LeBrun 2008), extreme heat (De Bono et al. 2004; Comrie 2007; Kaiser et al. 2007; Mora et al. 2017), and fires (Alston 2010; Stephens et al. 2014).

The coastal or hillside erosion leads to loss of assets and are associated to hurricanes, typhoons and storms (Scott et al. 2012; Mora et al. 2018), flooding (Haile et al. 2013; Mora et al. 2017), landslides (Tsai et al. 2011), heatwaves (Dobney et al. 2010), and fires (Teague et al. 2010; Oloruntoba 2013). Human health issues, such as the incidence of pathogen and vector borne diseases (such as malaria, dengue, leptospirosis, rift valley fever) are associated with flooding (Epstein 2001; Gubler et al. 2001; Mustafa and Wrathall 2011) and droughts (as people start to rely on unprotected sources of water and as dry conditions favors the inhalation of fungus; Calow et al. 2010; Stanke et al. 2013). Respiratory distress and heat strokes are associated with extreme heat, heat island effects (Gronlund et al. 2014), and fires (Hurteau et al. 2014).

\subsection{How EbA interventions have been measured and evaluated to date?}

Of the 58 projects we reviewed, $60 \%$ included at least one indicator to track the impact(s) of their EbA interventions. More than half (55\%) of all projects only included indicators to track project outputs (such as number of hectares restored). Thirty-six percent of all projects presented indicators to track outcomes and $29 \%$ of all projects presented indicators to track both outputs and outcomes. Table 1 in the supplementary material provides details on the specific indicators used by each project to measure their outputs and/or outcomes. Indicators used to measure adaptation outcomes varied widely across projects. The most commonly chosen indicators to measure outcomes included "change in income" (used by $27 \%$ of projects that measured outcomes) and "change in agriculture productivity" (9\%). The most common indicators used to measure outputs included "number of hectares restored" (used by $28 \%$ of projects that measured outputs), "number of hectares protected" (11\%), and "number of people trained" $(31 \%)$.

In our review, the majority of the EbA projects had not identified or reported on outcome indicators. This could be due to several factors. First, the adaptation outcome to be achieved by project activities is not clear, and so is not the outcome indicator to be measured. Second, as the outcomes of many EbA projects that focus on ecosystem restoration will only be apparent after several years, potentially even decades after project implementation (Holl et al. 2001; Birch et al. 2010), many projects may not have resources to do the long-term monitoring needed to document potential adaptation outcomes. Third, many donors do not require outcome indicators to be reported from EbA projects, so there is little motivation for projects to undertake such monitoring on outcomes. Finally, the lack of a set of common indicators that can be used by adaptation projects to report on their progress makes monitoring outcomes more difficult than in other projects (such as mitigation projects, where a single metric - avoided greenhouse gas emissions - can be used) (Ford et al. 2013; Ford et al. 2015; Leiter et al. 2019). Therefore, two of those limiting factors could be addressed by clearly stating the outcomes to be achieved, and by having a clearly understanding of what should be measured. 


\subsection{What is the set of indicators that can capture the broad diversity of outcomes achieved by EbA?}

Based on the 13 outcomes identified and indicators used by donors, institutions, and international frameworks, we suggest a set of seven indicators that can be used to measure the adaptation outcomes of EbA (Table 2). We identified one indicator to address adaptation outcomes related to "assets," one related to "food security," one related to "livelihoods," two related to "safety and resource security," and two related to "health." These indicators do not specifically address improvements in governance, knowledge, and adaptive capacity as those are output indicators that do not provide information on the achievement of adaptation outcomes. The same way that the suggested indicators do not focus on on-the-ground EbA implementation or on the ecological components of the interventions, such as hectares of mangrove restored or number of trees planted. The indicators proposed here are ultimate, "gold standard" indicators that one should measure to address whether an adaptation outcome has been achieved.

These suggested indicators are worth using, not only because they directly address the adaptation outcomes that can be achieved through EbA, but because they can be assessed through data that has already been collected by national or regional censuses, data that is often used to measure development or other goals. This is the case of indicator no. 3 proposed here (see Table 2) as people's income from specific activities may already be collected through time by national or regional censuses. Furthermore, indicator no. 1 is listed within those to track the global targets of the Sendai Framework for Disaster Risk Reduction, and indicators nos.2, 3, 4, and 5 are within those listed to track the achievement of the Sustainable Development Goals, making the indicators suggested here aligned with those that countries must report on. Likewise, some of the indicators proposed here are the same as those recommended by well-known organizations (i.e., World Health Organization) to measure human wellbeing (nos. 6 and 7), while others (nos. 1 and 4) by well-known institutions (i.e., GIZ) to measure adaptation goals (Hammill et al. 2014).

We acknowledge, however, that there are a few challenges in applying the indicators proposed by this study. These include the issues of causality (Ford et al. 2013; Ford et al. 2015) (i.e., whether EbA is the factor leading to the identified outcomes), the limited data available to assess the indicators in certain locations and the fact that adaptation outcomes take time to become identifiable and can be subject to evolving objectives and conditions (Noble et al. 2014). We are aware that our indicators may be more aligned to the concept of contribution than attribution or causality. Nevertheless, when applied systematically and regularly, the suggested indicators could offer the opportunity to build the much-needed evidence on the successful of the intervention in achieving adaptation outcomes (as highlighted by Ford et al. 201). In addition, if projects can be sustained after the initial funding ends, and if appropriate indicators are used to monitor long-term outcomes, those issues can be overcome to some extent. Another way to overcome some of those issues is to clearly link the EbA activities implemented to the adaptation outcome to be achieved and articulate the assumptions taken. Unless EbA projects do a better job of articulating clear adaptation outcomes and implementing indicators to measure these outcomes, it will be difficult to rigorously evaluate how effective EbA projects are in delivering adaptation benefits to human communities.

Identifying short-term indicators that can be collected through time, and indicate how the results acquired can lead to the outcome, could also help advance the monitoring of EbA. To facilitate that, we have also provided a list of mid-term, process-based indicators that can be tracked when the "gold standard" indicators cannot, due to lack of data and/or time and resource constraints (Table 2). 


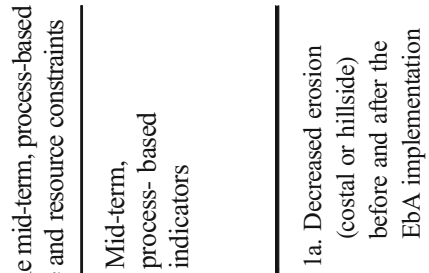

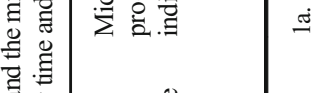

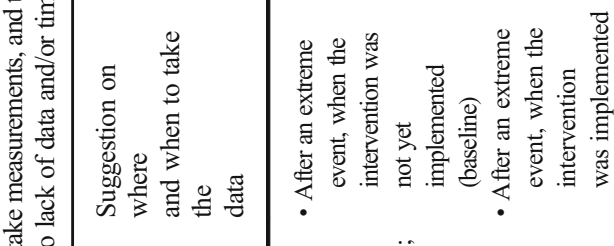

政

政

잉

을.

尊

过

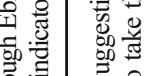

娄

จ

㞼

o.

등 음

害

o.

产

.5.

논

흉

․․․

政

呇

!.

要

密

몽

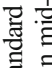

密.

s

品

政

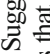

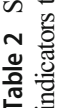

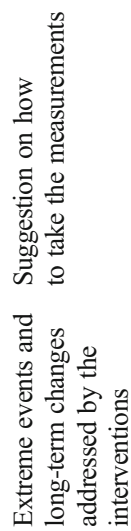

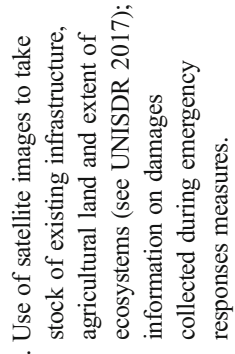

-

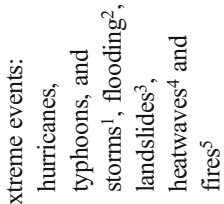

肴

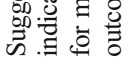

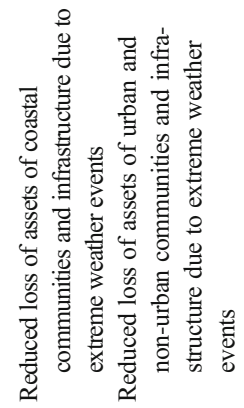

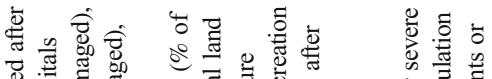

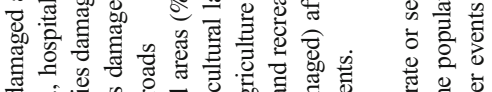

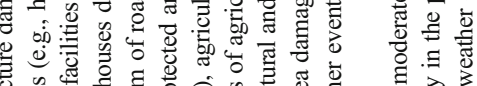

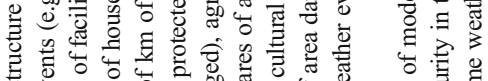

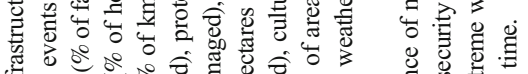

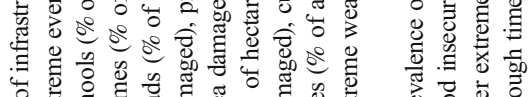

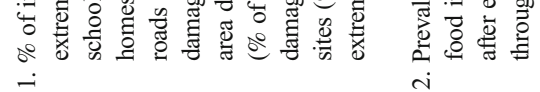

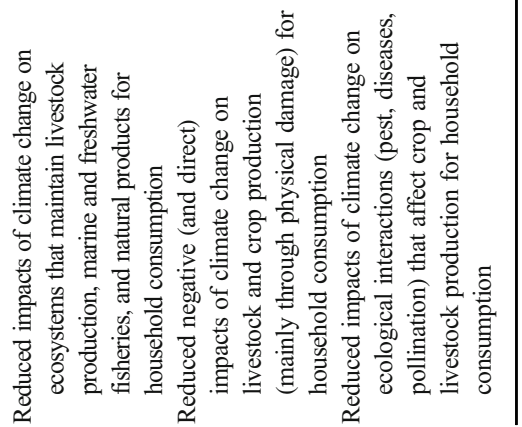




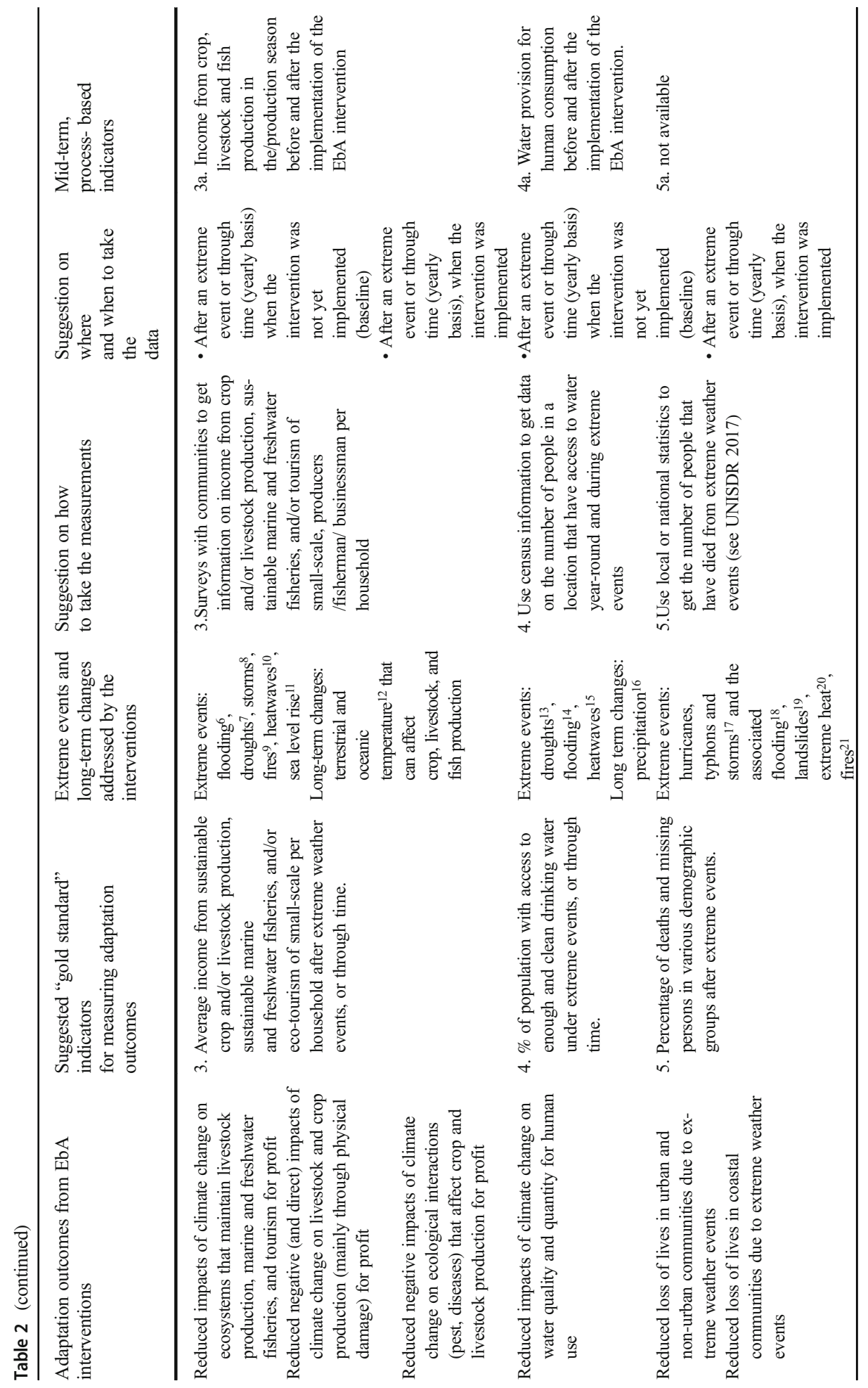




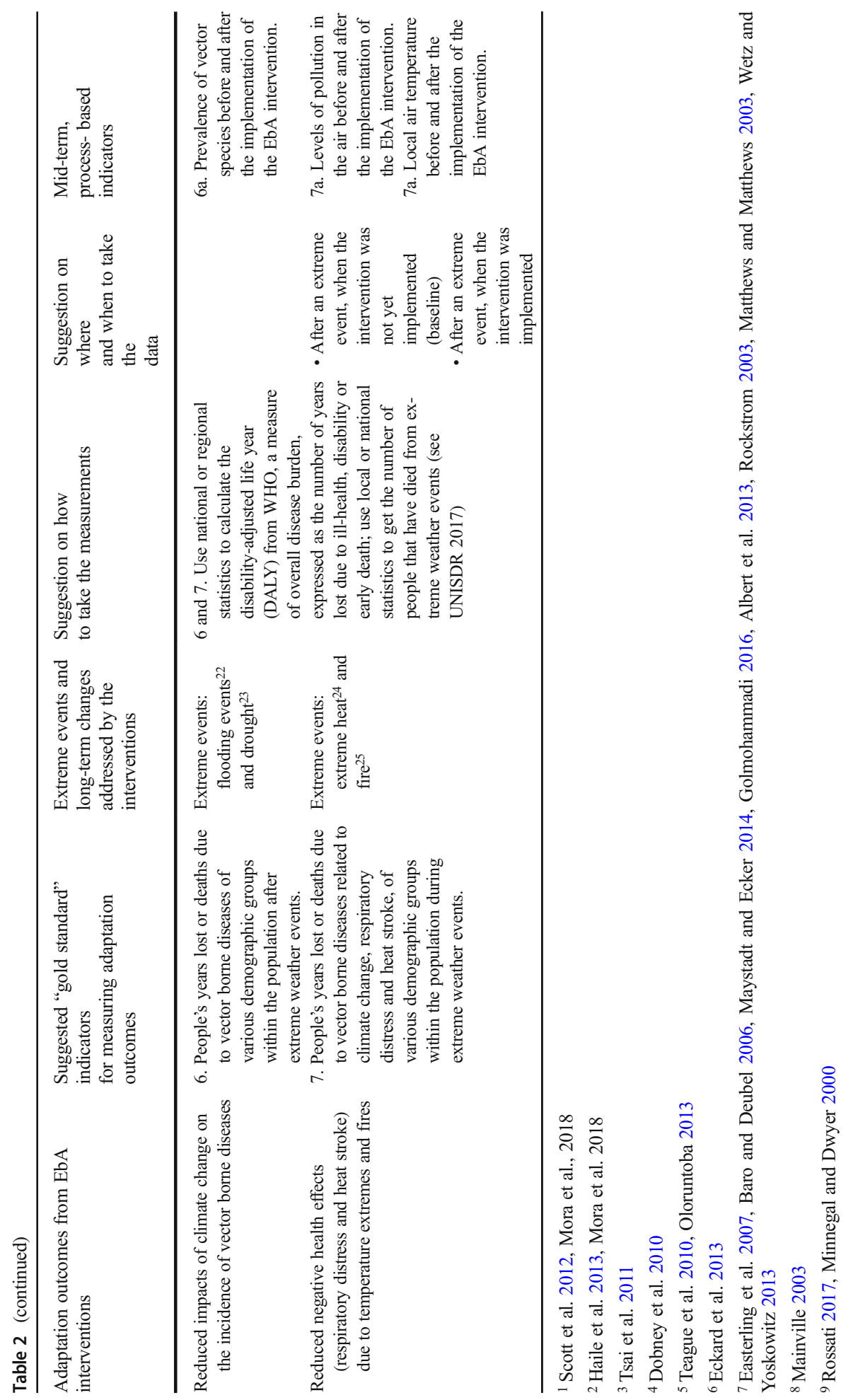




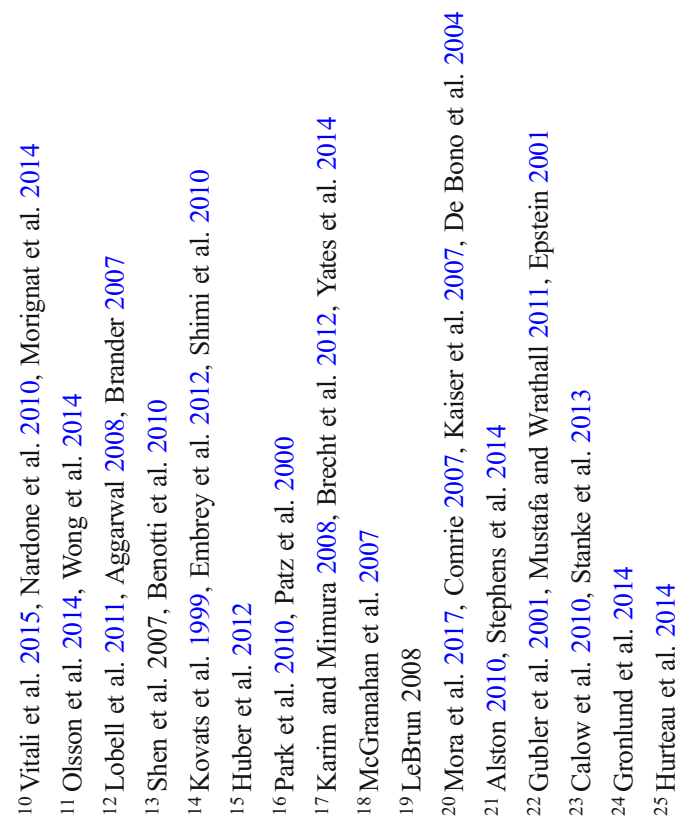




\subsubsection{How suggested indicators could be applied?}

We suggest that all indicators proposed here are measured both (a) prior to the implementation of the EbA intervention (i.e., baseline), and (b) either through time (on a yearly basis) or after an extreme weather event. Measurements of the same indicator pre- and post-intervention are necessary to determine whether the adaptation outcomes of the EbA intervention were achieved (Ford et al. 2015). However, we believe that is up to the practitioner in charge of implementing the EbA intervention to decide what type of adaptation action is needed, how the adaptation actions should be implemented, and what success means in a specific context. The spatial scale of implementation also needs to be decided by those designing and implementing the intervention. Likewise, the specific threshold used to determine whether the adaptation outcome has been achieved has also to be decided by the practitioner as the magnitude and type of interventions depends on the socio-economic conditions of the target site and on the changes driven by climate that the intervention is trying to address. Table 2 presents specific suggestions on how, where, and when the information related to each suggested indicator should be collected.

\subsubsection{How the use of the indicators be promoted?}

The seven EbA indicators suggested here can be used by governments, donors, project managers, and policy makers to track the impacts of EbA activities in achieving adaptation outcomes. In addition to using this common set of indicators, we suggest that project implementers clearly state the adaptation outcomes to be achieved by EbA interventions and prepare a theory of change (see McKinnon and Hole 2015), which can be used to explicitly link interventions to intended outcomes. Using a theory of change can improve project design, implementation, and monitoring (see Conservation International 2012; Bours et al. 2014; McKinnon and Hole 2015) as assumptions, short-term indicators, and outcome indicators can be listed, allowing an adaptive project management with the adaptation outcome in mind.

For projects to make progress in measuring the adaptation outcomes achieved through EbA, governments and donors will need to agree on and adopt a common set of indicators (such as the set proposed here), and access and provide funds for long-term monitoring. Some donors, such as the Green Climate Fund (e.g., GCF 2016) have recently included indicators that track outcomes of adaptation projects (e.g., "changes in... loss of lives and economic assets due to the impacts of climate-related disasters in the area of intervention"), indicators that are similar to those proposed in this study. However, most donors only require output indicators to be monitored. In addition, donors interested in supporting and implementing EbA projects need to acknowledge that monitoring systems will need to remain in place over long-time frames and provide funds to maintaining monitoring efforts support, so the adaptation outcomes of those projects can be robustly measured. We suggest that key donors of EbA initiatives (such as IKI and GEF) also start to require that project implementers report on the adaptation outcome indicators instead of just output indicators, and that governments do the same to track their adaptation progress as part of the Paris Agreement. There is also a need to include a common set of adaptation indicators in national and subnational adaptation monitoring and evaluation systems, as many currently lack indicators to monitor adaptation outcomes (Leiter 2015). These steps would facilitate systematic and consistent reporting on the achievements of EbA projects.

The implementation of appropriate EbA interventions, the identification of how they can help achieve adaptation outcomes, and the monitoring of these outcomes could ensure that funding is guided towards EbA interventions that are the most successful in delivering certain adaptation 
outcomes (Spearman and MacGray 2011; McKinnon and Hole 2015; Raymond et al. 2017). Identifying and focusing on successful EbA interventions could help increase funding to naturebased solutions to climate change, which receive less than $2 \%$ of global climate finance (Climate Policy Initiative 2017) and are largely ignored by the private sector (Goldstein et al. 2018).

\section{Conclusions}

Ecosystem-based adaptation projects are increasingly being implemented as part of adaptation efforts around the world, yet there is a lack of understanding on what should be measured to track the success of these projects. Our study summarized the activities, outcomes and indicators of 58 EbA projects, including both on-the-ground efforts to manage and restore ecosystems, or biodiversity, or the implementation of sustainable agricultural practices, and EbA-enabling activities, such as the development of policies and plans to increase the protection and restoration of ecosystems and biodiversity. These EbA projects aim to address a variety of adaptation outcomes to ultimately contribute to improving five dimensions of human wellbeing that are impacted by climate change: assets, livelihoods, food security, safety and resource security and health. However, many did not clearly state the intended adaptation outcomes to be achieved and did not include any indicators to monitor progress towards these outcomes.

This work, which combined an extensive review of EbA projects, recommendations from practitioners and experts from non-governmental organizations, academia and funder agencies and guided by theoretical literature, provides the much-needed information on a common set of indicators to monitor and evaluate EbA activities and projects. Indicators proposed through this study are relevant as many are used to measure development or other goals, such as the Sendai Framework for Disaster Risk Reduction and the Sustainable Development Goals. For $\mathrm{EbA}$ to be considered an important approach for climate change adaptation, there is a need to test the feasibility of the indicators proposed here and promote their use so a robust understanding of the role of EbA in providing adaptation benefits is developed. The list of adaptation indicators proposed here is a key step towards making that happen.

Acknowledgements We would like to thank Angela Andrade, Lauretta Burke, Netra Chhetri, Jonathan Cook, Giacomo Fedele, Carla Friedrich, Allie Goldstein, Anna Kontorov, Timo Leiter, Sarah Mack, Susi Menazza, Daouda Ndiaye, Felix Ries, and Ali Raza Rizvi for feedback on the adaptation outcomes and indicators during a workshop organized by Conservation International in October 2016.

Funding information This work was funded by a grant provided by Betty and Gordon Moore

\section{References}

Aggarwal P (2008) Global climate change and Indian agriculture: impacts, adaptation and mitigation. Indian J Agric Sci 78(11):911-919

Albert IJM, Beck HE, Crosbie RS, de Jeu RAM, Liu YY, Podger GM, Timbal B, Viney NR (2013) The Millennium Drought in southeast Australia (2001-2009): Natural and human causes and implications for water resources, ecosystems, economy, and society. Water Resour Res 49(2):1040-1057

Alston M (2010) Gender and climate change in Australia. J Sociol 47(1):53-70

Andrade A, Fernandez B, Gatti, R C (2010) Building resilience to climate change. IUCN. p. 164

Baro M, Deubel TF (2006) Persistent hunger: perspectives on vulnerability, famine, and food security in subSaharan Africa. Annu Rev Anthropol 35:521-538

Benotti MJ, Stanford BD, Snyder SA (2010) Impact of drought on wastewater contaminants in an urban water supply. J Environ Qual 39:1196-2000 
Birch JC, Newton AC, Aquino CA, Cantarello E, Echeverria C, Kitzberger T, Schiappacasse I, Gavarito NT (2010) Cost-effectiveness of dryland forest restoration evaluated by spatial analysis of ecosystem services. Proc Natl Acad Sci U S A 107(50):21925-21930

Bours D, McGinn C, Pringle P (2014) Guidance note 2: selecting indicators for climate change adaptation programming. https://ukcip.ouce.ox.ac.uk/wp-content/PDFs/MandE-Guidance-Note2.pdf. Accessed 6 Nov 2019

Brander KM (2007) Global fish production and climate change. Proc Natl Acad Sci U S A 104(50):19709-19714

Brecht H, Dasgupta S, Laplante B, Murray S, Wheeler D (2012) Sea-level rise and storm surges: high stakes for a small number of developing countries. J Environ Dev 21(1):120-138

Calow RC, MacDonald AM, Nicol AL, Robins NS (2010) Ground water security and drought in Africa: linking availability, access, and demand. Ground Water 48(2):246-256

CBD (2009) Connecting biodiversity and climate change mitigation and adaptation. Report of the second ad Hoc Technical Expert Group and Climate Change. CBD Technical series No. 41. Secretariat of the convention on Biological Diversity.

Climate policy Initiative (2017) Global landscape of climate finance. p. 18

Comrie A (2007) Climate Change and Human Health (2207). Geography Compass 1/3: 325-339. https://doi. org/10.1111/j.1749-8198.2007.00037.x

Conservation International (2012) Constructing theories of change for ecosystem-based adaptation projects. https:/www.conservation.org/docs/default-source/publication-pdfs/constructing-theories-of-change-forecosystem-based-adaptation.pdf?Status=Master\&sfvrsn=1fd83348_3. Accessed 6 Nov 2019

De Bono A, Peduzzi P, Luser S, Guiliani G (2004) Impacts of Summer 2003 heat wave in Europe. Environment Alert Bulletin. United Nations Environment Programme.

Dobney K, Baker C, Chapman L, Quinn A (2010) The future cost to the United Kingdom's railway network of heat-related delays and buckles caused by the predicted increase in high summer temperatures owing to climate change. Proc Inst Mech Eng Part 224:25-34

Doswald N, Munroe R, Roe D, Giuliani A, Castelli I, Stephens J, Moller I, Spencer T, Vira B, Reid H (2014) Effectiveness of ecosystem-based approaches for adaptation: review of the evidence-base. Clim Dev 6(2): 185-201

Easterling WE, Aggarwal PK, Batima P, Brander KM, et al. (2007) Food, fibre and forest products. Climate Change 2007: Impacts, Adaptation and Vulnerability. Contribution of Working Group II to the Fourth Assessment Report of the Intergovernmental Panel on Climate Change, M.L. Parry, O.F. Canziani, J.P. Palutikof, P.J. van der Linden and C.E. Hanson, Eds., Cambridge University Press, Cambridge, UK 273-313.

Eckard R.B, Christie K, Rawnsley R (2013) Living in a warmer world Salinger J. (ed) 144-157 (CSIRO, Auckland, 2013).

Emanuel K (2005) Increasing destructiveness of tropical cyclones over the past 30 years. Nature 436:686-688

Embrey S, Remais JV, Hess J (2012) Climate change and ecosystem disruption: the health impacts of the North American rocky mountain pine beetle infestation. Am. J. Public Health 102:818-827

Emerton L, Baig S, Saleem M (2009) Valuing biodiversity: the economic case for biodiversity conservation in the Maldives. IUCN publication. https:/portals.iucn.org/library/sites/library/files/documents/2009-115.pdf. Accessed 6 Nov 2019

Epstein PR (2001) Climate change and emerging infectious diseases. Microbes Infect 3:747-754

Ford JD, Berrang Ford L, Lesnikowski A, Barrera M, Heymann SJ (2013) How to track climate change adaptation: A typology of approaches for national-level application. Ecol Soc 18(3):40. https://doi. org/10.5751/ES-05732-180340

Ford JD, Berrang-Ford L, Biesbroek R, Araos M, Austin SE, Lesnikowski A (2015) Adaptation tracking for a post-2015 climate agreement. Nat Clim Chang 5:967-969

GCF (2016) Further development of indicators in the performance measurement frameworks. https://www. greenclimate.fund/documents/20182/184476/GCF_B.12_13_-_Further_development_of_indicators_in the performance_measurement_frameworks.pdf/30 $1 \mathrm{f} 1 \mathrm{f} 9 \mathrm{a} \overline{5}-98 \overline{\mathrm{a}} \overline{5}-483 \mathrm{~b}-\overline{85} 53-\mathrm{e} 306 \mathrm{~b} 3 \mathrm{c} 3 \overline{9} 4 \overline{\mathrm{e}} 2$. Accessed $\overline{6}$ Nov 2019

Goldstein A, Turner WR, Gladstone J, Hole DG (2018) The private sector's climate change risk and adaptation blind spots. Nat Clim Chang 9:18-25

Golmohammadi F (2016) Drought and it's environmental and socio-economic impacts in the viewpoint of farmers in south Khorasan province-East of Iran. Indian Res J Ext Educ 1:238-244

Gronlund CJ, Zanobetti A, Schwartz JD, Wellenius GA, O’Neill MS (2014) Heat, heat waves, and hospital admissions among the elderly in the United States, 1992-2006. Environ Health Perspect 122:1187-1188

Gubler DJ, Reiter P, Ebi KL, Yap W, Nasci R, Patz JA (2001) Climate variability and change in the United States: potential impacts on vector-and rodent-borne diseases. Environ Health Perspect 109:223-233

Haile AT, Kusters K, Wageshon N (2013) Loss and damage from flooding in the Gambela region, Ethiopia. Int J Global Warming 4(4):483-497 
Hammill A, Dekens J, Leiter T, Olivier J, Klockemann L, Stock E, Glaser A (2014) Repository of adaptation indicators. Real case examples from national monitoring and evaluation systems. GIZ. p. 74. file://D:/ Documents\%20and\%20Settings/cdonatti/Documents/back\%20up\%20july13th2017/OneDrive\%20Old/ Old\%20OneDrive/Moore\%20center\%20funding_eba\%20hotspots/relevant\%20publications-indicators/ giz2014-en-climate-adaptation-indicator-repository.pdf

Harvey CA, Martinez-Rodriguez MR, Cardeas JM et al (2017) The use of ecosystem-based adaptation practices by smallholder farmers in Central America. Agric Ecosyst Environ 246:279-290

Holl KD, Loik ME, Lin EH, Samuels IA (2001) Tropical montane forest restoration in Costa Rica: overcoming barriers to dispersal and establishment. Restor Ecol 8(4):339-349

Huber V, Wagner C, Gerten D, Adrian R (2012) To bloom or not to bloom: contrasting responses of cyanobacteria to recent heat waves explained by critical thresholds of abiotic drivers. Oecologia 169(1): 245-256

Hurteau MD, Westerlin AL, Wiedinmyer C, Bryant BP (2014) Projected effects of climate and development on California wildfire emissions through 2100. Environ Sci Technol 48:2298-2304

IIED (2018) Nature-based solutions delivering national-level adaptation and mitigation goals. IIED briefing papers. http://pubs.iied.org/pdfs/17484IIED.pdf. Accessed 6 Nov 2019

Jones HP, Hole DG, Zavaleta ES (2012) Harnessing nature to help people adapt to climate change. Nat Clim Chang 2(7):504-509

Kahn ME (2003) Two measures of progress in adapting to climate change. Global Environ Change - Hum Policy Dimen 13:307-312. https://doi.org/10.1016/S0959-3780(03)00052-9

Kaiser R, Le Tertre A, Schwartz J, Gotway CA, Daley WR, Rubin CH (2007) The effect of the 1995 heat wave in Chicago on all-cause and cause-specific mortality. Am J Public Health 97:158-S162

Karim MF, Mimura N (2008) Impacts of climate change and sea-level rise on cyclonic storm surge floods in Bangladesh. Glob Environ Chang 18(3):490-500

Kovats RS, Haines A, Stanwell-Smith R et al (1999) Climate change and human health in Europe. Br Med J 318 : 1682-1685

Leiter T (2015) Linking monitoring and evaluation of adaptation to climate change across scales: avenues of and practical approaches. N Dir Eval 147:117-127

Leiter T, Pringle P (2018) Pitfalls and potential of measuring climate change adaptation through adaptation metrics. In: Christiansen L, Martinez G, Naswa P (eds) Adaptation metrics: perspectives on measuring, aggregating and comparing adaptation results. UNEP DTU Partnership, Copenhagen

Leiter T, Olhoff A, Al Azar R, Barmby V, Bours D, Clement VWC, Dale TW, Davies C, Jacobs H (2019) Adaptation metrics: current landscape and evolving practices. Rotterdam and Washington, DC. Available online at www.gca.org

Lobell DB, Schlenker W, Costa-Roberts J (2011) Climate trends and global crop production since 1980. Science 333(6042):616-620

Mainville DY (2003) Disasters and development in agricultural input markets: bean seed markets in Honduras after hurricane Mitch. Disasters 27:154-171

Matthews WJ, Matthews EW (2003) Effects of drought on fish across axes of space, time and ecological complexity. Freshw Biol 48(6):1232-1253

Maystadt J-F, Ecker O (2014) Extreme weather and civil war in Somalia: does drought fuel conflict through livestock price shocks? Am J Agric Econ 96(4):1157-1182

McGranahan G, Balk D, Anderson B (2007) The rising tide: assessing the risks of climate change and human settlements in low elevation coastal zones. Environ Urban 19(1):17-37

McKinnon MC, Hole DG (2015) Exploring program theory to enhance monitoring and evaluation in Ecosystembased adaptation projects. N Dir Eval 147:49-60

McKinnon MC, Cheng SH, Dupre S, Edmond J, Garside R, Glew L, Holland MB, Levine E, Masuda YJ, Miller D, Oliveira I, Revenaz J, Roe D, Shamer S, Wilkie D, Wongbusarakum S, Woddhouse E (2016) What are the effects of nature conservation on human well-being? A systematic map of empirical evidence from developing countries. Environ Evid 5(8):1-25

Milman A, Jagannathan K (2017) Conceptualization and implementation of ecosystem-based adaptation. Clim Chang 142:113-127. https://doi.org/10.1007/s10584-017-1933-0

Mimura NR, Pulwarty S, Duc D M, et al. (2014) Adaptation planning and implementation. In: Climate Change 2014: Impacts, Adaptation, and Vulnerability. Part A: Global and Sectoral Aspects. Contribution of Working Group II to the Fifth Assessment Report of the Intergovernmental Panel on Climate Change [Field, C.B., V.R. Barros, D.J. Dokken, K.J. Mach, M.D. Mastrandrea, T.E. Bilir, M. Chatterjee, K.L. Ebi, Y.O. Estrada, R.C. Genova, B. Girma, E.S. Kissel, A.N. Levy, S. MacCracken, P.R.

Minnegal M, Dwyer PD (2000) Responses to a drought in the interior lowlands of Papua New Guinea: a comparison of bedamuni and Kubo Konai. Hum Ecol 28(4):493-526 
Moberg F, Rönnbäck P (2003) Ecosystem services of the tropical seascape: Interactions, substitutions and restoration. Ocean Coast Manag 46:27-46

Mohamed M (2007) Economic valuation of coral reefs: a case study of the costs and benefits of improved management of Dhigali Haa, a marine protected in Baa atoll, Maldives. University of Canterbury, Master thesis

Mora C, Dousset B, Caldwell IR et al (2017) Global risk of deadly heat. Nat Clim Chang 7:501-506

Mora C et al. (2018) Broad threat to humanity from cumulative climate hazards intensified by greenhouse gas emissions. Nature Climate Change 8:1062-1071

Mori AS, Spies TA, Sudmeier-Rieux K, Andrade A (2013) Reframing ecosystem management in the era of climate change: issues and knowledge from forests. Biol Conserv 165:115-212

Morignat E, Perrin JB, Gay E, Vinard JL, Calavas D, Hénaux V (2014) Assessment of the impact of the 2003 and 2006 heat waves on cattle mortality in France. PLoS One. https://doi.org/10.1371/journal.pone.0093176

Munang R, Thiaw I, Alverson K, Mumba M, Liu J, Rivington M (2013) Climate change and Ecosystem-based Adaptation: a new pragmatic approach to buffering climate change impacts. Curr Opin Environ Sustain 5:1-5

Munroe R, Roe D, Doswald N, Spencer T, Moller I, Vira B, Hannah R, Andreas K, Alessandra G, Ivan C, Stephens J (2012) Review of the evidence base for ecosystem-based approaches for adaptation to climate change. Environ Evid 1:13

Mustafa D, Wrathall D (2011) Basin floods of 2010: souring of a Faustian bargain? Water Alternatives 4(1):72-85

Nardone A, Ronchi B, Lacetera N, Ranieri MS, Bernabucci U (2010) Effects of climate changes on animal production and sustainability of livestock systems. Livest Sci 130(1-3):57-69

Naumann S, Davis M, Munang R et al (2013) The social dimension of ecosystem-based adaptation. UNEP Policy Series: Ecosystem Management. Policy Brief 12.

Noble, IR, Huq S, Anokhin YA, Carmin J, Goudou D, Lansigan FP, Osman-Elasha B, Villamizar A (2014) Adaptation needs and options. In: Climate Change 2014: Impacts, Adaptation, and Vulnerability. Part A: Global and Sectoral Aspects. Contribution of Working Group II to the Fifth Assessment Report of the Intergovernmental Panel on Climate Change [Field, C.B., V.R. Barros, D.J. Dokken, K.J. Mach, M.D. Mastrandrea, T.E. Bilir, M. Chatterjee, K.L. Ebi, Y.O. Estrada, R.C. Genova, B. Girma, E.S. Kissel, A.N. Levy, S. MacCracken, P.R. Mastrandrea, and L.L.White (eds.)]. Cambridge University Press, Cambridge, United Kingdom and New York, NY, USA, pp. 833-868.

Olivier J, Leiter T, Linke J (2013) Adaptation made to measure: a guidebook to the design and results-based monitoring of climate change adaptation projects. Deutsche Gesellschaft fur Internationale Zusammenarbeit (GIZ).

Oloruntoba R (2013) Plans never go according to plan: an empirical analysis of challenges to plans during the 2009 Victoria bushfires. Technol Forecast Soc Change 80:1674-1702

Olsson L, Opondo M, Tshakert A et al (2014) In: Climate change 2014: impacts, adaptation, and vulnerability. Part A: global and sectoral aspects. Contribution of Working Group II to the Fifth Assessment Report of the Intergovernmental Panel on Climate Change [Field, C.B., V.R. Barros, D.J. Dokken, K.J. Mach, M.D. Mastrandrea, T.E. Bilir, M. Chatterjee, K.L. Ebi, Y.O. Estrada, R.C. Genova, B. Girma, E.S. Kissel, A.N. Levy, S. MacCracken, P.R. Mastrandrea, and L.L.White (eds.)]. Cambridge University Press, Cambridge, United Kingdom and New York, NY, USA.

Park HJ, Duan L, Kim B, Mitchell MJ, Shibata H (2010) Potential effects of climate change and variability on watershed biogeochemical processes and water quality in Northeast Asia. Environ Int 36(2):212-225

Patz PA, McGeehin MA, Bernard SM, Ebi KL, Epstein PR, Grambsch A, Gubler DJ, Reither P, Romieu I, Rose JB, Samet JM, Trtanj J (2000) The potential health impacts of climate variability and change for the United States: executive summary of the report of the health sector of the U.S. National Assessment.

Raymond CM, Frantzeskaki N, Kabisch N, Berry P, Breil M, Nita MR, Geneletti D, Calfapietra C (2017) A framework for assessing and implementing the co-benefits of nature-based solutions in urban areas. Environ. Sci Policy 77:15-24

Reid H (2011) Improving the evidence for ecosystem-based adaptation. Sustainable Development Opinion Paper. http://pubs.iied.org/pdfs/17109IIED.pdf. Accessed 6 Nov 2019

Rockstrom J (2003) Water for food and nature in drought-prone tropics: vapour shift in rain-fed agriculture. Philos Trans R Soc Lond Ser B Biol Sci 358(1440):1997-2009

Rossati A (2017) Global warming and its health impact. Int J Occup Environ Med 8:7-20

Scott D, Simpson MC, Sim R (2012) The vulnerability of Caribbean coastal tourism to scenarios of climate change related sea level rise. J Sustain Tour 20:883-898

Shen C, Wang W-C, Hao Z, Gong W (2007) Exceptional drought events over eastern China during the last five centuries. Clim Chang 85:453-471

Shimi AC, Parvin GA, Biswas C, Shaw R (2010) Impact and adaptation to flood: a focus on water supply, sanitation and health problems of rural community in Bangladesh. Disaster Prev Manage: An International Journal 19(3):298-313

SNIFFER (2012) Climate change adaptation-related indicators. ER23 Final Report, Edinburgh, p 25 
Spearman M, MacGray H (2011) Making adaptation count: concepts and options for monitoring and evaluation of climate change adaptation. http://pdf.wri.org/making_adaptation_count. Accessed 6 Nov 2019

Stanke C, Kerac M, Prudhomme C, Medlock J, Murray V (2013) Health effects of drought: a systematic review of the evidence. Plos Curr 5. DOI: https://doi.org/10.1371/currents.dis.7a2cee9e980f91ad7697b570bcc4b004.

Stephens SL, Burrows N, Buyantuyev A, Gray RW, Keane RE, Kubian R, Liu S, Seijo F, Shu L, Tolhurst KG, van Wagtendonk JW (2014) Temperate and boreal forest mega-fires: characteristics and challenges. Front Ecol Environ 12:115-122

Teague B, McLeod R, Pascoe S (2010) 2009 Victorian Bushfires Royal Commission final report: summary. Available at http://www.royalcommission.vic.gov.au/finaldocuments/summary/HR/VBRC_Summary_HR. pdf. Accessed 6 Nov 2019

Tsai H-T, Tseng C-J, Tzeng S-Y, Wu J, Day J-D (2011) The impacts of natural hazards on Taiwan's tourism industry. Nat Hazards 62:83-91

UKCIP (2004) Costing the impacts of climate change in the UK. Implementation report Oxford UK. https://www.ukcip.org.uk/wp-content/PDFs/Costings_overview.pdf. Accessed 6 Nov 2019

UNEP (2012) Making the case for ecosystems-based adaptation: building resilience to climate change. UNEP, Nairobi, Kenya

UNEP (2015) Implementation of resolutions adopted by the United Nations Environment Assembly at its first session. Addendum Resolution 1/8: ecosystem-based adaptation. Report of the Executive Director.

UNFCCC (2015) Database on ecosystem-based approaches to adaptation. https://unfecc. int/topics/resilience/resources/adaptation-databases.

United Nations (2015) The Paris Agreement. https://unfccc.int/sites/default/files/english_paris_agreement.pdf

Vignola R, Harvey CA, Bautista-Solis P, Avelino J, Rapidel B, Donatti CI, Martinez MR (2015) Ecosystembased adaptation for smallholder farmers: definitions, opportunities and constraints. Agric Ecosyst Environ 211:126-132

Vitali A, Felici A, Esposito S, Bernabucci U (2015) Effects of heat waves on mortality of dairy cows. Proc MACSUR Int Livestock Model Res Colloq 6(1):15-16

Wetz MS, Yoskowitz DW (2013) An 'extreme' future for estuaries? Effects of extreme climatic events on estuarine water quality and ecology. Mar Pollut Bull 69(1-2):7-18

Wong PP, Losada IJ, Gattuso J-P et al (2014). Costal systems and low-lying areas. In: Climate change 2014: impacts, adaptation, and vulnerability. Part A: Global and Sectoral Aspects. Contribution of Working Group II to the Fifth Assessment Report of the Intergovernmental Panel on Climate Change [Field, C.B., V.R. Barros, D.J. Dokken, K.J. Mach, M.D. Mastrandrea, T.E. Bilir, M. Chatterjee, K.L. Ebi, Y.O. Estrada, R.C. Genova, B. Girma, E.S. Kissel, A.N. Levy, S. MacCracken, P.R. Mastrandrea, and L.L.White (eds.)]. Cambridge University Press, Cambridge, United Kingdom and New York, NY, USA, pp. 361-409.

World Bank (2009) Convenient solutions to an inconvenient truth: ecosystem-based approaches to climate change. https://siteresources.worldbank.org/ENVIRONMENT/Resources/ESW_EcosystemBasedApp.pdf. Accessed 6 Nov 2019

Yates D, Luna BQ, Rasmussen R, Bratcher D et al (2014) Assessing climate change hazards to electric power infrastructure: a sandy case study. IEEE Power Energy Mag 12(5):66-75

Publisher's note Springer Nature remains neutral with regard to jurisdictional claims in published maps and institutional affiliations.

\section{Affiliations}

\section{Camila I. Donatti ${ }^{1} \cdot$ Celia A. Harvey $^{1,2} \cdot$ David Hole $^{1} \cdot$ Steven N. Panfil ${ }^{3} \cdot$ Hanna Schurman ${ }^{4}$}

1 The Betty and Gordon Moore Center for Science, Conservation International, 2011 Crystal Dr, Arlington, VA 22202, USA

2 Monteverde Institute, Monteverde, Puntarenas, Costa Rica

3 Green Climate Fund Agency, Conservation International, 2011 Crystal Dr, Arlington, VA 22202, USA

4 McCourt School of Public Policy, Georgetown University, 37th and O Streets NW, Washington, DC 20057, USA 